ORIGINAL ARTICLE

\title{
Human fetal and maternal corticotrophin releasing hormone responses to acute stress
}

\author{
R Gitau, N M Fisk, V Glover
}

Arch Dis Child Fetal Neonatal Ed 2004;89:F29-F32

See end of article for authors' affiliations ....................

Correspondence to: Professor Glover, Fetal and Neonatal Stress Research Group, Wolfson and Weston Research Centre for Family Health, Institute of Reproductive and Developmental Biology, Faculty of Medicine, Imperial College London, Hammersmith Campus, Du Cane Road, London W12 ONN, UK:

v.glover@imperial.ac.uk

Accepted 25 January 2003
Objectives: To study the effect of acute stress, caused by intrauterine needling at the intrahepatic vein (IHV), on fetal plasma concentrations of corticotrophin releasing hormone (CRH), and to compare paired fetal and maternal samples for CRH concentration to determine the extent of their joint control.

Design: Venous blood samples were obtained from fetuses (gestational age 17-38 weeks) undergoing fetal blood sampling $(n=29)$ or intrauterine transfusion $(n=17)$ through either the IHV or the placental cord insertion (PCI).

Setting: The Centre for Fetal Care, Queen Charlotte's and Chelsea Hospital, London, UK.

Patients: Pregnant women undergoing clinically indicated fetal blood sampling or intrauterine blood/ platelet transfusion.

Results: Fetal plasma cortisol increased with intrahepatic vein transfusion (mean (SD) cortisol response $\Delta 64.7(54.5) \mathrm{nmol} / \mathrm{l} ; \mathrm{p}<0.0001, \mathrm{n}=11$ ), and fetal corticotrophin concentrations were higher after IHV $(\mathrm{n}=7)$ than $\mathrm{PCl}$ needling $(\mathrm{n}=6)$. Neither fetal nor maternal plasma CRH increased after IHV transfusion. Fetal CRH levels did not rise with gestation, whereas maternal CRH levels did $(r=0.58 ; \mathrm{n}=36$; $\mathrm{p}<0.0001)$. There was a modest correlation between paired maternal and fetal values $(r=0.36 ; \mathrm{n}=36$; $\mathrm{p}=0.03)$

Conclusions: Acute fetal stress, caused by IHV needling of the fetal abdomen, resulted in hypothalamicpituitary-adrenal axis activation, as shown by a rise in fetal cortisol and corticotrophin. However, it did not result in measurable CRH release into fetal plasma. This suggests that fetal plasma $\mathrm{CRH}$ is not derived from the hypophyseal-portal circulation, but from another source, presumably the placenta.
A lthough corticotrophin releasing hormone $(\mathrm{CRH})$ is normally very low in adult plasma, maternal concentrations increase substantially during pregnancy, with the largest rise in the two weeks before delivery. ${ }^{1-3}$ High maternal levels have been associated with preterm labour. ${ }^{4}$ Although CRH is present in fetal plasma, ${ }^{2}$ few studies have measured fetal $\mathrm{CRH}^{256}$ and none have examined levels in response to stress.

We report CRH concentrations in human fetal venous samples obtained by needling at the placental cord insertion (PCI) or the intrahepatic vein (IHV), either before and after transfusion or from a single fetal blood sampling procedure. The PCI is not innervated, and we have shown in previous studies that needling at this site is not stressful for the fetus, whereas needling through the IHV, which involves piercing the fetal abdomen, is stressful..$^{7-9}$ Such procedures using the IHV cause a rise in fetal venous concentrations of the stress hormones cortisol, $\beta$ endorphin, and noradrenaline (norepinephrine), and also Doppler changes suggestive of blood flow redistribution to the brain..$^{7-10}$

Our hypothesis was that, unlike other stress hormones, fetal peripheral blood levels of $\mathrm{CRH}$ would not rise after needling at the IHV, as stress related release of CRH should be confined to the hypophyseal-portal circulation, and, as in the adult, not reach the plasma in any measurable quantity. ${ }^{3}$ This would be in contrast with the suggestion of Lockwood et $a l^{6}$ that some fetal plasma CRH may derive from the fetal hypothalamus.

Maternal samples were obtained at the same time as the fetal samples, to determine the relation between maternal and fetal $\mathrm{CRH}$, because of the possibility that they are jointly influenced by placental as opposed to hypothalamic CRH, or that there is transplacental passage from mother to fetus, as we have previously shown for cortisol. ${ }^{11}$ Finally, we con- firmed fetal hypothalamic-pituitary-adrenal axis responsivity to acute stress by measuring cortisol and corticotrophin concentrations. ${ }^{79}$ Although corticotrophin has been measured in fetal blood, ${ }^{56}$ the fetal coticotrophin response to a stressful procedure has not.

\section{MATERIALS AND METHODS \\ Patients}

Women undergoing clinically indicated fetal blood sampling or intrauterine blood/platelet transfusion at the Centre for Fetal Care, Queen Charlotte's and Chelsea Hospital, London, UK were recruited. Ethical approval for the study was granted by the Hammersmith Hospitals ethics committee. Cortisol and $\beta$ endorphin results from some of these fetuses have been reported previously.

Inclusion criteria were singleton fetuses appropriately grown for gestational age and structurally normal on ultrasound. Exclusion criteria were similar to those used in our previous studies. ${ }^{7-10}$ The indications for fetal blood sampling and for intrauterine transfusion were also similar to those used previously. ${ }^{7-10}$

The site of ultrasound guided fetal blood sampling or transfusion was chosen by the operator on the basis of technical factors and ease of approach. Neither fetal neuromuscular blockade nor analgesia was used. The mothers did not receive sedation. Intravascular transfusion was performed as previously described..$^{7-10}$ Thirty two fetuses underwent procedures at the IHV, 11 of these receiving a blood transfusion. Fetal blood was obtained from 14 PCI procedures, six receiving blood transfusions. Mean (SD) duration of trans-

Abbreviations: $\mathrm{CRH}$, corticotrophin releasing hormone; IHV, intrahepatic vein; $\mathrm{PCl}$, placental cord insertion 


\begin{tabular}{llll} 
Table 1 & Characteristics of blood samples & & \\
\hline & Before IHV transfusion & Before PCl transfusion & Needling \\
\hline Number & 16 & 6 & 66 \\
Gestational age (weeks) & $29.1(5.10)$ & $30.5(4.59)$ & $28.4(4.88)$ \\
Packed cell volume & $31.6(7.11)$ & $29.8(5.46)$ & $34.0(7.20)$ \\
Cortisol (nmol/l) & $60.7(41.8$ to 88.2$)$ & $50.6(9.63$ to 266$)$ & $57(50.0$ to 65.4$)$ \\
$\mathrm{CRH}(\mathrm{pg} / \mathrm{ml})$ & $219(191$ to 250$)$ & $210(163$ to 271$)$ & $210(47.6)$ \\
Maternal cortisol (nmol/l) & $719(613$ to 843$)$ & $769(598$ to 989$)$ & $736(240)$ \\
Maternal CRH (pg/ml) & $368(293$ to 463$)$ & $377(313$ to 454$)$ & $334(305$ to 366$)$ \\
Time to access $(\mathrm{min})$ & $3.02(1.84$ to 4.96$)$ & $2.74(0.91$ to 8.23$)$ & $3.40(2.63$ to 4.41$)$ \\
Duration (min) & $17.9(10.1)$ & $11.9(5.49)$ & \\
\hline
\end{tabular}

Values are mean (SD) or geometric mean (anti-ln 95\%Cl).

$\mathrm{IHV}$, Intrahepatic vein; PCl, placental cord insertion; CRH, corticotrophin releasing hormone.

fusion was 16.5 (9.8) minutes, and the (geometric) mean (anti-ln 95\% confidence interval) duration of needling to access the fetal circulation was 4.26 (3.26 to 5.58) minutes.

\section{Blood samples}

After collection of clinical samples, up to $1-2 \mathrm{ml}$ venous fetal blood was placed in a chilled heparinised tube. If there was sufficient, an additional $0.5-1 \mathrm{ml}$ was placed into a chilled EDTA tube for corticotrophin determination. Maternal blood $(7 \mathrm{ml})$ was collected by venepuncture into a heparinised Vacutainer (Becton Dickinson, Meylan, France) immediately before transabdominal needle insertion and again 1020 minutes after the procedure.

Trasylol $(50 \mu \mathrm{l} / \mathrm{ml}$ (500 KIU); Bayer AG) was added to all blood samples immediately after collection. Bloods were prepared as described previously. ${ }^{9}$

\section{Assays}

Plasma CRH was assayed using a direct plasma radioimmunoassay (Peninsula, San Carlos, California, USA). The lower limit of sensitivity was $10 \mathrm{pg} / \mathrm{ml}$, and the assay coefficient of variation was $10.5 \%$. Cortisol was assayed using a standard solid phase radioimmunoassay (DPC, Los Angeles, California, USA); the lower limit of sensitivity was $10 \mathrm{nmol} / \mathrm{l}$, and the assay coefficient of variation was $5.3 \%$. Maternal and fetal plasma sample pairs were analysed in the same assay run. In general, cortisol was measured in parallel, but in a few cases, there was insufficient sample volume to measure cortisol as well as CRH. Limited sample volume also meant it was only possible to determine corticotrophin in a small number of blood samples taken before transfusions. EDTA plasma corticotrophin was assayed using a standard solid phase two site immunoradiometric assay (Nichols Institute Diagnostics, San Juan Capistrano, California, USA). The lower limit of sensitivity was $1.0 \mathrm{pg} / \mathrm{ml}$, and the assay coefficient of variation was $8.6 \%$.

\section{Statistical analysis}

Normally distributed data were analysed by standard parametric statistics using SPSS 10.0 for Windows (Chicago,

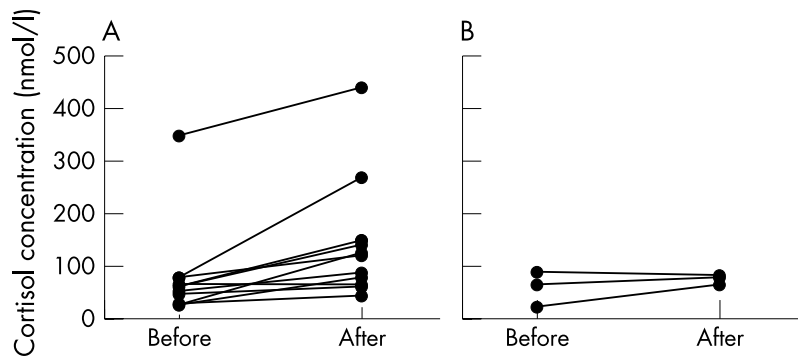

Figure 1 Fetal cortisol levels before and after transfusion at the intrahepatic vein (A) (paired $t$ test $p<0.001 ; n=11$ ) and at the placental cord insertion (B) (paired $t$ test $p=0.3 ; n=3$ ).
Illinois, USA). Non-parametric initial values (fetal cortisol and maternal CRH levels, time to access) and maternal and fetal transfusion data were first normalised by natural log transformation. Geometric means and anti-ln 95\% confidence intervals $(95 \% \mathrm{CI})$ are displayed. Responses to transfusions were analysed using $\Delta$ values (hormone concentration after transfusion stress - hormone concentration before transfusion stress).

\section{RESULTS}

\section{Fetal samples}

Table 1 gives details of the pre-transfusion and needling samples. Fetal plasma cortisol concentrations increased with transfusion at the IHV (fig lA); mean (SD) $\Delta 64.7$ (54.5) $\mathrm{nmol} / \mathrm{l}(\mathrm{n}=11, \mathrm{p}<0.0001)$. The few transfusions at the PCI with sufficient sample $(\mathrm{n}=3)$ showed no significant change (fig 1B). Corticotrophin levels were significantly higher in the needling only-that is, nontransfusion-samples from the IHV than from the PCI (88.1 (73.6) pg/ml $(\mathrm{n}=7) v 18.7$ (5.7) pg/ml $(\mathrm{n}=6)$; $\mathrm{p}=0.04$ ) (fig 2). There was insufficient plasma volume available to assay corticotrophin in the transfusion group samples.

Figures $3 \mathrm{~A}$ and $3 \mathrm{~B}$ show that there was no change in fetal CRH level with transfusion at either the IHV or PCI. Similarly, fetal CRH concentrations were similar after needling at the two sites (fig 3C).

There was no significant difference in $\Delta$ fetal CRH levels in procedures that involved transplacental insertion of the needle (median $\Delta 15 \mathrm{pg} / \mathrm{ml}$; range $(-40$ to 163$) ; \mathrm{n}=11$ ) and those that did not (median $\Delta-4 \mathrm{pg} / \mathrm{ml} ;(-51$ to 362 ); $\mathrm{n}=6$ ). Similarly, there was no significant difference in initial fetal CRH levels in procedures that involved transplacental insertion of the needle (mean (SD) 185 (49.4) pg/ml; $\mathrm{n}=20)$ and those that did not $(216(48.0) \mathrm{pg} / \mathrm{ml} ; \mathrm{n}=26)$.

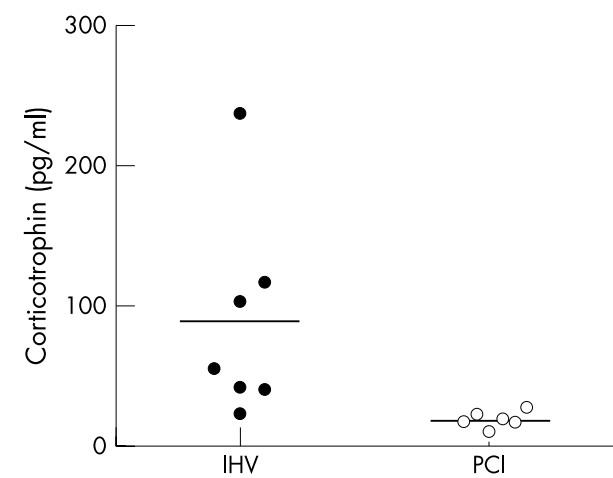

Figure 2 Fetal corticotrophin levels after blood samplings from the intrahepatic vein $(\mathrm{IHV})$ and placental cord insertion $(\mathrm{PCI})$ sites ( $t$ test $\mathrm{p}=0.04 ; \mathrm{IHV}, \mathrm{n}=7 ; \mathrm{PCl}, \mathrm{n}=6$ ) 

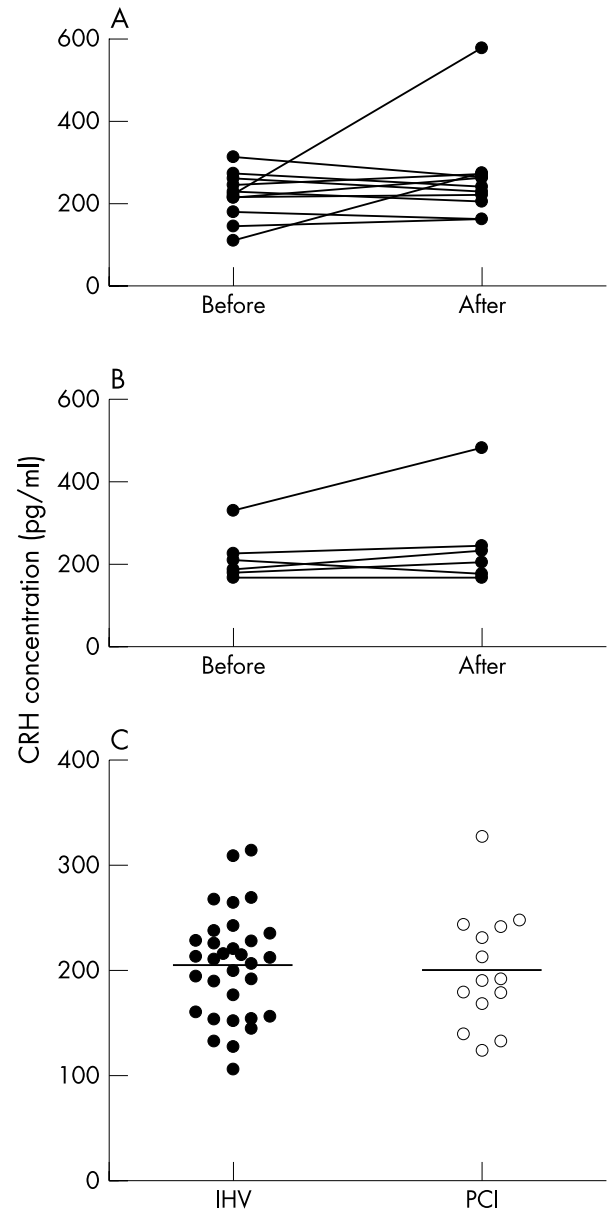

Figure 3 Fetal corticotrophin releasing hormone (CRH) concentration (A) before and after transfusion at the intrahepatic vein (IHV) site (paired $t$ test $p=0.2 ; n=11)$, (B) before and after transfusion at the placental cord insertion ( $\mathrm{PCl}$ ) site (paired $t$ test $\mathrm{p}=0.3 ; \mathrm{n}=6$ ), and (C) from IHV and $\mathrm{PCl}$ blood samplings (unpaired t test $\mathrm{p}=0.9 ; \mathrm{IHV}, \mathrm{n}=32 ; \mathrm{PCl}$, $\mathrm{n}=14)$.

\section{MATERNAL AND FETAL CRH}

Maternal CRH levels did not change with transfusion at either site (fig 4).

Figure 5 shows the relation between paired fetal and maternal CRH levels and gestational age between 20 and 38 weeks. Whereas maternal levels increased substantially with advancing gestation, fetal levels did not (maternal $r=0.58, \mathrm{n}=36, \mathrm{p}<0.0001 ; \mathrm{y}=98.4+1.04$ anti-ln $\mathrm{x}$; anti-

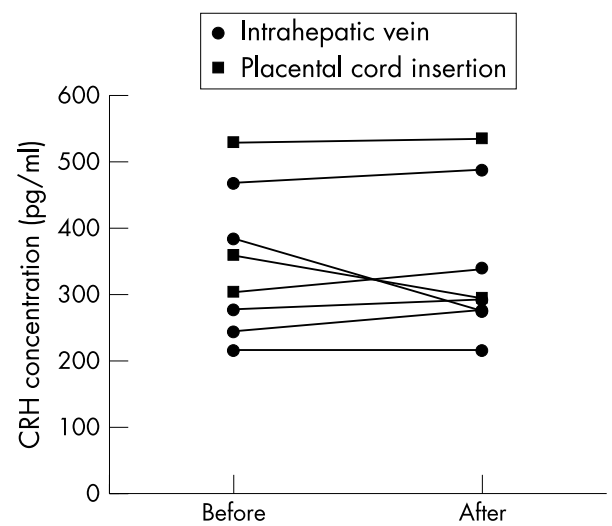

Figure 4 Maternal corticotrophin releasing hormone (CRH) levels before and after transfusion (paired $t$ test $\mathrm{p}=0.8 ; \mathrm{n}=8$ ).

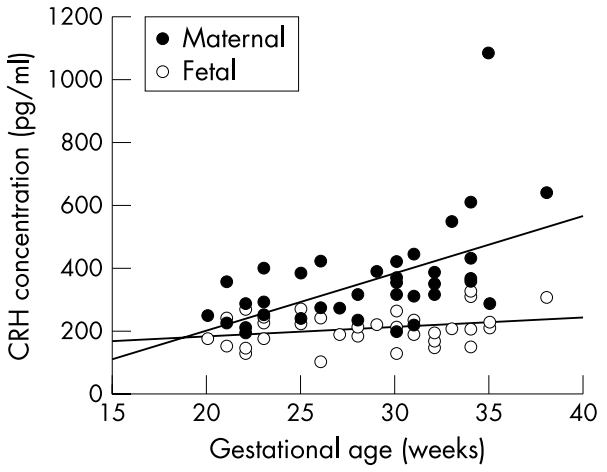

Figure 5 Relation between paired maternal and fetal corticotrophin releasing hormone $(C R H)$ levels and gestational age $(n=36)$. Maternal $\mathrm{CRH}$, Pearson $r=0.58, \mathrm{p}<0.0001, \mathrm{y}=98.4+1.04$ anti-In $\mathrm{x}$, anti- $\ln$ $95 \% \mathrm{Cl}$ for slope (1.02 to 1.07); fetal CRH, Pearson $r=0.27$, ns.

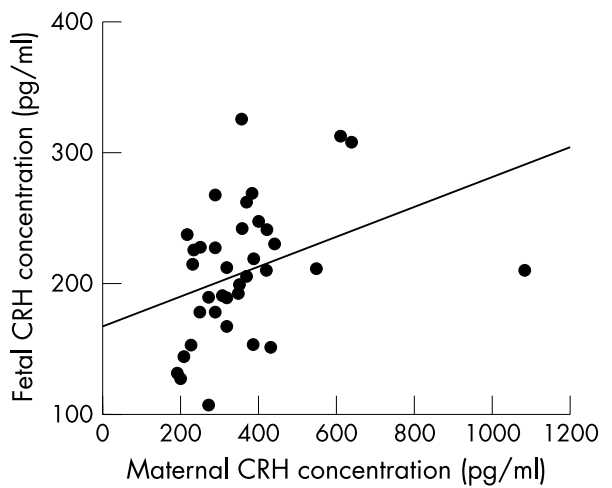

Figure 6 Paired maternal and fetal corticotrophin releasing hormone (CRH) levels. Pearson $r=0.36, p=0.03, n=36, y=170+0.11 x$, (0.01 to 0.22).

ln 95\%CI for slope (1.02 to 1.07); fetal $r=0.27$ ). Figure 6 shows a modest correlation between paired fetal and maternal CRH levels $(r=0.36, \mathrm{n}=36, \mathrm{p}=0.03$; $\mathrm{y}=170+0.11 \mathrm{x} ;(0.01$ to 0.22$))$. This correlation remained significant even on removal of the outlier.

There was no significant relation between initial maternal or fetal CRH and cortisol levels, except for a correlation between fetal CRH and fetal cortisol levels $(r=0.32, \mathrm{n}=38$, $\mathrm{p}=0.048$; table 2).

\section{DISCUSSION}

This study confirmed our hypothesis, in that needling the IHV was not associated with an increase in fetal plasma CRH levels, either after transfusions, which we confirmed are associated with an increase in cortisol (fig 1), or after fetal blood sampling only procedures, which we showed were associated with an increase in corticotrophin (fig 2). This shows that the fetal hypothalamus-pituitary-adrenal axis,

Table 2 Correlations between maternal and fetal corticotrophin releasing hormone (CRH) and cortisol levels (after needling or before transfusion)

\begin{tabular}{lll}
\hline & Maternal CRH & Fetal CRH \\
\hline Maternal & $r=-0.002 ;$ & $r=0.04 ;$ \\
cortisol & $\mathrm{n}=33 ; \mathrm{ns}$ & $\mathrm{n}=31 ; \mathrm{ns}$ \\
Fetal cortisol & $r=0.11 ;$ & $r=0.32$ \\
& $\mathrm{n}=32 ; \mathrm{ns}$ & $\mathrm{n}=38 ; \mathrm{p}=0.048$ \\
\hline
\end{tabular}


although functional from mid-gestation, ${ }^{9}$ does not involve any measurable release of $\mathrm{CRH}$ into fetal plasma. This is similar to the situation in adults.

The finding that transfusion at the IHV leads to a rise in fetal cortisol supports our previous findings, ${ }^{79}$ and the lack of effect on fetal CRH levels indicates that placental CRH does not mediate the acute response to the stress of percutaneous needling in the human fetus.

The corticotrophin response to stress has not been previously studied in the human fetus. The increase in levels at the IHV but not the PCI, after needling, is consistent with a more rapid release than that of cortisol. This is compatible with release from the pituitary rather than the adrenal, and is also similar to findings in adults and animal models. ${ }^{12}$ In a previous study we have shown that noradrenaline, which is also released more quickly than cortisol, was increased in initial values after IHV fetal blood sampling compared with PCI. ${ }^{8}$

Our results suggest that fetal plasma CRH is derived from another source, presumably the placenta. It is well established that the placenta produces large amounts of $\mathrm{CRH}^{4}{ }^{13-16}$ and that both maternal and fetal aspects of the syncytiotrophoblast contain binding proteins for $\mathrm{CRH}$, with significantly more on the maternal side. ${ }^{17-19}$ This study shows that, whereas maternal plasma CRH levels increased substantially with gestation, fetal levels did not (fig 5); indeed, although there was some joint control of fetal and maternal CRH levels, it was not substantial $(r=0.36)$. The results suggest that the placenta secretes CRH preferentially into the maternal rather than the fetal circulation as gestation increases..$^{20}$ Our results do not preclude a fetal plasma $\mathrm{CRH}$ rise in the last two weeks of gestation, or infection or hypoxic stress mediating a fetal CRH rise immediately before delivery, although Lockwood et $a l^{6}$ found no increase up to 40 weeks gestation.

It is unlikely that there is any substantial direct maternal to fetal transfer across the placenta, both because of the nature of $\mathrm{CRH}$ (a 41 amino acid peptide) and the divergent patterns of maternal and fetal cortisol with increasing gestation. Our results in this regard are similar to those of Lockwood et al. ${ }^{6}$ Our correlation between maternal and fetal levels of 0.36 is also in the same range as that found in two previous studies. ${ }^{5} 6$

It is of interest that maternal CRH did not change with transfusion. There is sometimes concern that transplacental needling procedures may induce preterm labour through increased release of placental CRH. We found no evidence of this, although increased CRH release over a longer time period than measured immediately after transfusion remains a possibility.

The lack of correlation between maternal CRH and cortisol supports the findings of previous studies. ${ }^{1221}$ However, Lockwood et $a l^{6}$ found a correlation of 0.41 between maternal $\mathrm{CRH}$ and fetal cortisol, which we did not observe here. Our finding of a significant correlation of 0.32 between fetal CRH and fetal cortisol is of interest, and may suggest joint control in the fetal compartment, either possibly driving the other. However, as Lockwood et $a l^{6}$ failed to find such a correlation, our finding must be interpreted with caution. Also, maternal peptides may elicit fetal effects, through release of placental hormones into the fetal compartment. ${ }^{22}$

Lockwood et $a l^{6}$ have suggested that the dissociation between maternal and fetal plasma CRH levels was because a proportion of the fetal CRH derived from the fetal hypothalamus. We show here that this is unlikely, and suggest, in contrast, that the plasma CRH in both circulations derives from the placenta, where they are, at least partially, under different control mechanisms. The fact that fetal plasma CRH, unlike maternal $\mathrm{CRH}$, does not rise substantially with gestation, at least until 38 weeks, makes it unlikely that it is involved in the normal triggering of parturition. One suggestion is that it stimulates adrenal dehydroepiandrosterone sulphate, which in turn acts as a precursor for oestradiol. ${ }^{23}$ At present, however, the role of fetal plasma CRH remains obscure.

\section{ACKNOWLEDGEMENTS}

We acknowledge support from the Henry Smith Charity, the Institute of Obstetrics and Gynaecology Trust, the John Ellerman Foundation, and the Children Nationwide Medical Research Foundation.

\section{Authors' affiliations}

R Gitau, V Glover, Fetal and Neonatal Stress Research Group, Wolfson and Weston Research Centre for Family Health, Institute of Reproductive and Developmental Biology, Faculty of Medicine, Imperial College London, London W12 ONN, UK

N M Fisk, Centre for Fetal Care, Queen Charlotte's and Chelsea Hospital, London W12 ONN, UK

\section{REFERENCES}

1 Campbell EA, Linton EA, Wolfe CD, et al. Plasma corticotropin-releasing hormone concentrations during pregnancy and parturition. J Clin Endocrinol Metab 1987;64:1054-9.

2 Goland RS, Wardlaw SL, Blum M, et al. Biologically active corticotropinreleasing hormone in maternal and fetal plasma during pregnancy. Am J Obstet Gynecol 1988;159:884-90.

3 Goland RS, Conwell IM, Warren WB, et al. Placental corticotropin-releasing hormone and pituitary-adrenal function during pregnancy.

Neuroendocrinology 1992;56:742-9.

4 Smith R. Alterations in the hypothalamic pituitary adrenal axis during pregnancy and the placental clock that determines the length of parturition. J Reprod Immunol 1998;39:215-20.

5 Economides D, Linton E, Nicolaides K, et al. Relationship between maternal and fetal corticotrophin-releasing hormone-41 and ACTH levels in human mid-trimester pregnancy. J Endocrinol 1987;114:497-501.

6 Lockwood CJ, Radunovic N, Nastic D, et al. Corticotropin-releasing hormone and related pituitary-adrenal axis hormones in fetal and maternal blood during the second half of pregnancy. J Perinat Med 1996;24:243-51.

7 Giannakoulopoulos X, Sepulveda W, Kourtis P, et al. Fetal plasma cortisol and beta-endorphin response to intrauterine needling. Lancet 1994;344:77-81.

8 Giannakoulopoulos X, Teixeira J, Fisk N, et al. Human fetal and maternal noradrenaline responses to invasive procedures. Pediat Res 1999;45:494-9.

9 Gitau R, Fisk NM, Teixeira JMA, et al. Fetal hypothalamic-pituitary-adrenal Stress responses to invasive procedures are independent of maternal responses. J Clin Endocrinol Metab 2001;86:104-9.

10 Teixeira JM, Glover V, Fisk NM. Acute cerebral redistribution in response to invasive procedures in the human fetus. Am J Obstet Gynecol 1999; 181:1018-25.

11 Gitau R, Cameron A, Fisk NM, et al. Fetal exposure to maternal cortisol. Lancet 1998;352:707-8.

12 Jezova D, Kvetnansky R, Tilders $F$, et al. Interaction of circulating catecholamines, CRF and AVP in the control of ACTH release during stress. In: Van Loon G, Kvetnansky R, McCarty R, et al. Stress. Neurochemical and Humoral mechanisms, Vol 1. New York: Gordon and Breach Science Publishers, 1989.

13 Nodwell A, Carmichael L, Fraser M, et al. Placental release of corticotrophinreleasing hormone across the umbilical circulation of the human newborn. Placenta 1999;20:197-202.

14 Fadalti M, Pezzani I, Cobellis L, et al. Placental corticotropin-releasing factor. An update. Ann N Y Acad Sci 2000;900:89-94.

15 Karteris E, Grammatopoulos DK, Randeva HS, et al. The role of corticotropinreleasing hormone receptors in placenta and fetal membranes during human pregnancy. Mol Genet Metab 2001;72:287-96.

16 Riley SC, Challis JR. Corticotrophin-releasing hormone production by the placenta and fetal membranes. Placenta 1991;12:105-19.

17 Saeed B, Fawcett M, Self C. Corticotropin-releasing hormone binding to the syncytiotrophoblast membranes. Eur J Clin Invest 2001;31:125-30.

18 Karteris E, Grammatopoulos D, Dai Y, et al. The human placenta and fetal membranes express the corticotropin-releasing hormone receptor lalpha (CRH-lalpha) and the CRH-C variant receptor. J Clin Endocrinol Metab 1998:83:1376-9.

19 Florio P, Franchini A, Reis FM, et al. Human placenta, chorion, amnion and decidua express different variants of corticotropin-releasing factor receptor messenger RNA. Placenta 2000;21:32-7.

20 Ruth V, Hallman M, Laatikainen T. Corticotropin-releasing hormone and cortisol in cord plasma in relation to gestational age, labor, and fetal distress. Am J Perinatol 1993; 10:115-18.

21 Goland RS, Wardlaw SL, Stark RI, et al. High levels of corticotropin-releasing hormone immunoactivity in maternal and fetal plasma during pregnancy. J Clin Endocrinol Metab 1986;63:1199-203.

22 Bajoria R, Peek MJ, Fisk NM. Maternal-to-fetal transfer of thyrotropinreleasing hormone in vivo. Am J Obstet Gynecol 1998;178:264-9.

23 Majzoub JA, McGregor JA, Lockwood CJ, et al. A central theory of preterm and term labor: putative role for corticotropin-releasing hormone. Am J Obstet Gynecol 1999; 180:S232-41. 